\title{
Prototype Pengaman Rumah Dari Bahaya Pencurian Berbasis Mikrokontroller Melalui Komunikasi Bluetooth
}

\author{
Meutia Safitri ${ }^{1}$, I Gusti Agung Pt. Raka Agung ${ }^{2}$, I Gst A. Komang Diafari Djuni ${ }^{3}$ \\ Program Studi Teknik Elektro, Fakultas Teknik, Universitas Udayana Denpasar- Bali \\ Email : Meutiasafitri21@gmail.com ${ }^{1}$, rakaagung@unud.ac.id ${ }^{2}$, igakdiafari@unud.ac.id ${ }^{\underline{3}}$
}

\begin{abstract}
Abstrak
Kelalaian penghuni dan minimnya sistem pengamanan rumah menjadi penyebab maraknya kasus pencurian. Perkembangan teknologi yang semakin pesat, menjadikan teknologi dapat diaplikasikan sebagai sistem keamanan pada rumah. Hal ini dapat menjadi solusi untuk permasalahan tersebut. Pada penelitian ini dikembangkan sistem pengamanan rumah dalam bentuk prototype. Penelitian ini menggunakan mikrokontroller yang dapat dikontrol menggunakan perangkat handphone melalui komunikasi bluetooth. Prototype terdiri dari keypad untuk memasukkan password sebagai pengganti kunci rumah, sensor PIR (Passive Infrared Receiver) sebagai pendeteksi pergerakan panas tubuh manusia, dan buzzer sebagai alarm. Hasil dari penelitian ini adalah prototype telah terealisasi dimana Motor servo sudah dapat membuka dan mengunci dengan memasukkan password yang benar. Pengaturan ON/OFF lampu penerangan, tampilan informasi pada LCD (Liquid Crystal Display), serta ON/OFF sensor PIR dari handphone android melalui komunikasi Bluetooth telah sesuai dengan perencanaan.
\end{abstract}

Kata kunci : prototype, mikrokontroller, bluetooth

\begin{abstract}
The negligence of residents and the lack of a house security system are the causes of the rampant cases of theft. Technological developments are increasingly rapid, making technology can be applied as a security system at home. This can be a solution to these problems. In this study a home security system was developed in the form of a prototype. This study uses a microcontroller that can be controlled using mobile devices via bluetooth communication. The prototype consists of a keypad to enter a password as a substitute for a home key, a PIR sensor as a detection of human body heat movements, and a buzzer as an alarm. The results of this study are that the prototype has been realized where the servo motor has been able to open and lock by entering the correct password. Setting ON / OFF lighting, display information on the LCD, and ON / OFF PIR sensor from an Android mobile phone via Bluetooth communication are in accordance with the plan.
\end{abstract}

Keywords: prototype, microcontroller, bluetooth

\section{PENDAHULUAN}

Pemanfaatan teknologi pada berbagai segi kehidupan manusia baik dalam kebutuhan rumah tangga, komersil, maupun industri sangat dirasakan kehadirannya. Adanya satu media kontrol seperti handphone, seorang pengguna dapat mengontrol alat - alat elektronik pada rumah seperti lampu penerangan dan akses keluar masuk hanya dengan menggunakan satu piranti saja yang secara tidak langsung memberikan efek kemudahan dan keamanan. Hal ini dapat menjadi solusi untuk maraknya pencurian akibat kelalaian penghuni dan minimnya sistem pengamanan rumah.

Oleh karena itu, penelitian ini dibuat sebuah prototype pengaman rumah berbasis arduino uno dengan memanfaatkan teknologi bluetooth yang ekonomis. Prototype ini bekerja dengan dua sistem di antaranya yang pertama adalah pengaman rumah dengan akses 
masuk menggunakan password, serta sistem kedua adalah dengan menggunakan handphone yang terhubung dengan mikrokontroller. Diharapkan Prototype ini dapat meningkatkan kualitas pengamanan dan kemudahan serta memberikan solusi atas masalah yang terkait sistem keamanan saat ini.

\section{KAJIAN PUSTAKA}

\subsection{Arduino}

Arduino merupakan papan mikrokontroller berbasis ATmega328 dengan bahasa pemrograman IDE arduino yang bersifat opensource. Dalam arduino terdapat loader USB untuk memprogram mikrokontroller. Total pin arduino yakni 20 pin $\mathrm{l} / \mathrm{O}$, terdiri dari 6 pin input analog dan 14 pin digital input/output [1]. Papan Arduino dapat dilihat pada Gambar 1.

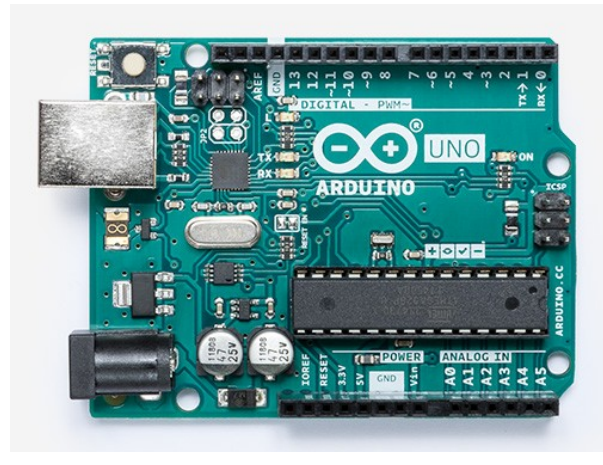

Gambar 1. Board Arduino [2]

\subsection{Module Bluetooth $\mathrm{HC}-05$}

Module Bluetooth HC-05 memiliki beberapa pin konektor yaitu RXD, TXD, VCC dan GND. Module bluetooth dapat berfungsi sebagai receiver (RX) maupun transceiver (TX). Rangkaian Bluetooth HC-05 dapat dilihat pada Gambar 2.

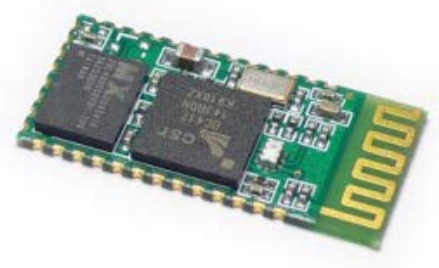

Gambar 2. Bluetooth HC-05 [3]

\section{3. $L C D$ Display}

$L C D$ berfungsi menampilkan informasi atau data berupa alfabet maupun numerik. LCD $16 \times 2$ terdiri dari 16 kolom dan 2 baris yang dilengkapi dengan backlight. Komponen ini berisikan 8 jalur data (D0-D7) yang berfungsi untuk memberikan data karakter yang ingin ditampilkan. LCD 16x2 ini dilengkapi pula dengan $E, R / W$ dan RS.[4].

\subsection{Sensor PIR (Passive Infrared Receiver) \\ Sensor PIR adalah sensor yang} berfungsi mendeteksi gerak dari suatu objek dengan pancaran sinar infrared. Sensor PIR bersifat pasif yang hanya menerima energi dari pancaran sinar inframerah [5]. Gambar 4 memperlihatkan bentuk sensor PIR yang digunakan.



Gambar 3. Sensor PIR [6]

\subsection{Motor servo}

Motor servo adalah sebuah perangkat yang terdiri dari motor DC, serangkaian gear, rangkaian control, dan potensiometer yang dirancang dengan sistem kontrol umpan balik loop tertutup (servo) sehingga dapat diatur untuk 
menentukan dan memastikan posisi sudut dari poros output motor. Motor servo dikendalikan dengan memberikan sinyal modulasi lebar melalui kabel control [7].

\section{METODE PERANCANGAN SISTEM}

Penelitian ini dilakukan di Laboratorium Teknik Digital dan Mikroprosesor Program Studi Teknik Elektro Fakultas Teknik Universitas Udayana, Kampus Bukit Jimbaran. Sumber data yang digunakan dalam penelitian ini diperoleh dari datasheet, jurnal, artikel dari internet, tugas akhir, dan buku-buku yang berhubungan dengan pembuatan Prototype sistem pengaman rumah serta dengan menggunakan metode pengumpulan data berupa studi literature.

Penelitian ini menggunakan bahan-bahan utama pendukung rancangan sistem pengaman rumah antara lain Arduino Uno sebagai pengolah data dan pengendali sistem, sensor PIR sebagai pendeteksi objek dengan memancarkan sinar infrared, bluetooth $\mathrm{HC}-05$ sebagai media komunikasi sistem dan pengguna, push button sebagai password untuk mengakses kunci pintu, buzzer sebagai alarm pengingat, motor servo sebagai kunci otomatis, LCD karakter 16x2 sebagai penampil informasi hasil konversi dan status. Perancangan, simulasi, dan realisasi perangkat keras secara skematik menggunakan software EAGLE untuk setiap blok rangkaian. Ilustrasi cara kerja dan diagram blok keseluruhan dari Prototype sistem keamanan pada rumah dapat dilihat dalam Gambar 4.

Gambar 4. Ilustrasi cara kerja sistem keamanan rumah

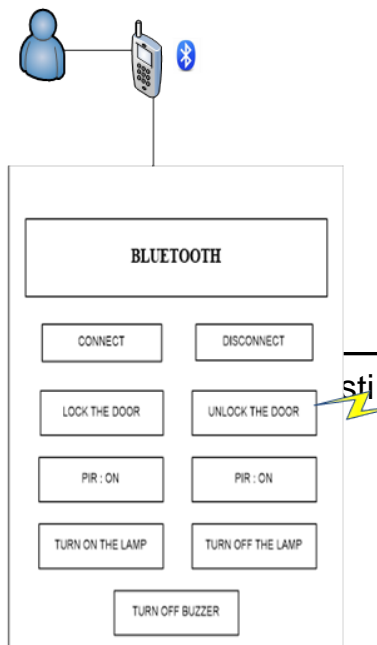

Adapun diagram blok sistem keamanan rumah yang dapat dilihat pada Gambar 5.

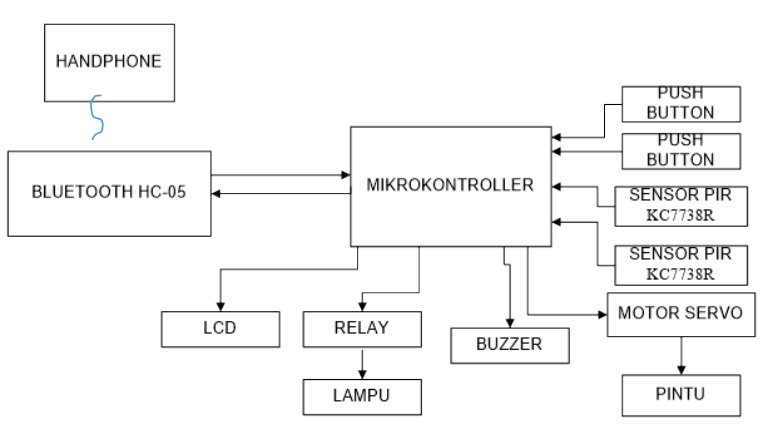

Gambar 5. Diagram blok sistem keamanan rumah

Setelah melakukan pengujian terhadap setiap perangkat keras yang telah direalisasikan guna mengetahui perangkat keras sudah bekerja dengan baik, maka tahap selanjutnya adalah melakukan perancangan software atau program rangkaian bahan-bahan tersebut sesuai dengan yang direncanakan dalam menunjang sistem pengaman rumah. Dan yang terakhir adalah dengan melakukan pengujian keseluruhan sistem alat dengan software yang telah dibuat.

\section{HASIL DAN PEMBAHASAN \\ 4.1. Realisasi Hasil Perancangan Sistem}

Prototype pengaman rumah yang terdiri dari satu buah arduino Uno, satu buah Bluetooth HC-05, 12 buah push button sebagai keypad, satu buah buzzer, satu buah LCD, dua buah sensor pir, dua buah relay serta bagian kedua adalah handphone yang berfungsi sebagai media control yang dapat mengirim dan menerima informasi data hasil dari pembacaan sensor oleh pergerakan objek. Realisasi hasil perancangan prototype sistem pengaman rumah dapat dilihat pada Gambar 6. 


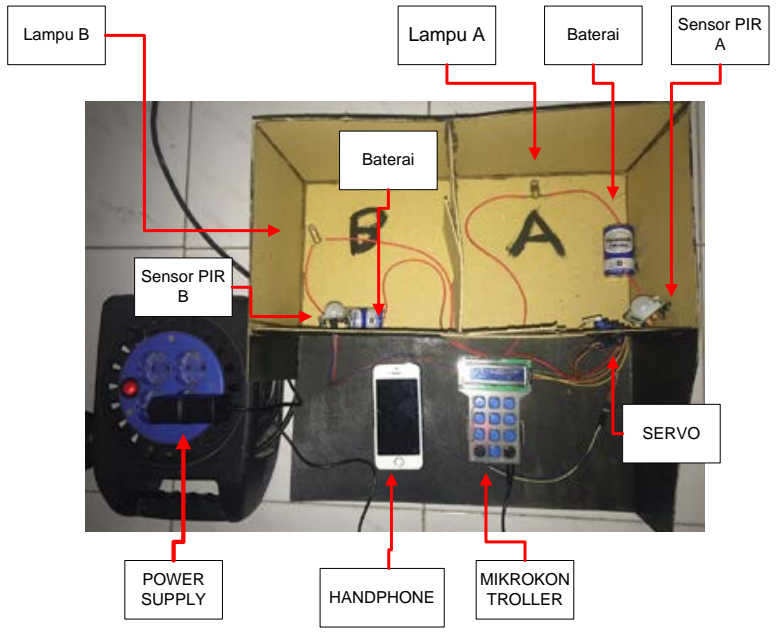

Gambar 6. Realisasi hasil perancangan sistem

\subsection{Pengujian dan pembahasan rangkaian LCD 16x2}

Pada pengujian password menggunakan rangkaian LCD dan mikrokontroler Arduino. Pengujian ini dapat dilihat pada Gambar 7. LCD 16x2 memiliki panjang kolom password yang terdiri dari 8 karakter numeric. Kolom ini digunakan untuk memasukkan password yang sudah diatur dengan menekan " $E$ " maka muncul tampilan "INPUT PASSWORD". Pada Gambar 8 memperlihatkan tampilan "Door Unlocked!" yang menandakan bahwa kunci terbuka dengan tambahan "Lockdown in 5" pada baris kedua yang menandakan akan terkunci kembali setelah 5 detik. Tampilan "Door Locked!" pada baris pertama yang menandakan pintu sudah terkunci setelah 5 detik dapat dilihat seperti pada Gambar 9.

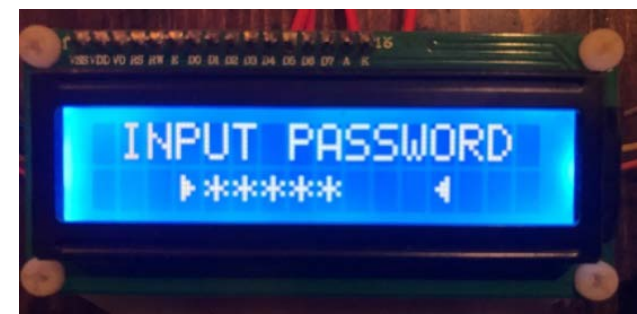

Gambar 7. Tampilan LCD saat memasukkan password

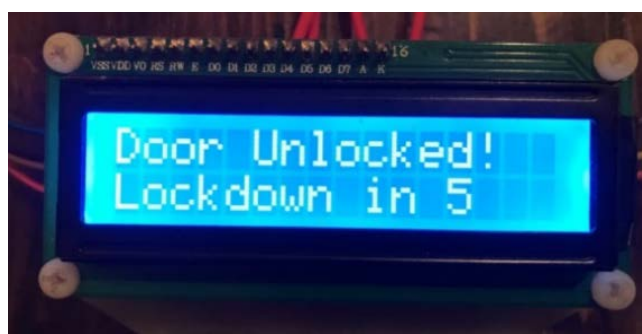

Gambar 8. Tampilan LCD saat kunci pintu terbuka

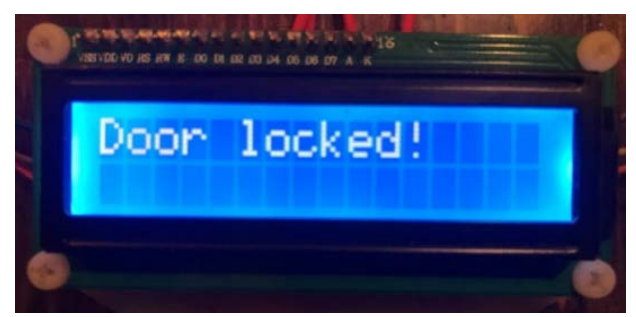

Gambar 9. Tampilan LCD saat pintu terkunci

\subsection{Pengujian dan pembahasan rangkaian motor servo}

Prototype pengaman rumah melalui komunikasi Bluetooth menggunakan motor servo dan mikrokontroller Arduino dimana dalam komponen servo terdapat potensiometer dan controller servo.

Pada penentuan posisi servo, servo akan bernilai close apabila diberikan pulsa $\mathrm{n}$ sebesar $1 \mathrm{~ms}<=\mathrm{n}<$ $1.5 \mathrm{~ms}$ dengan posisi sudut 0 derajat seperti yang ditujukan pada gambar 10 . Servo juga dapat bernilai close apabila diberikan pulsa $\mathrm{n}$ sebesar $1.5 \mathrm{~ms}<=\mathrm{n}<$ 2 ms dengan posisi sudut 90 derajat dan bernilai open apabila diberikan pulsa sebesar 2 ms dengan posisi sudut 180 derajat, dapat dilihat pada Gambar 11.

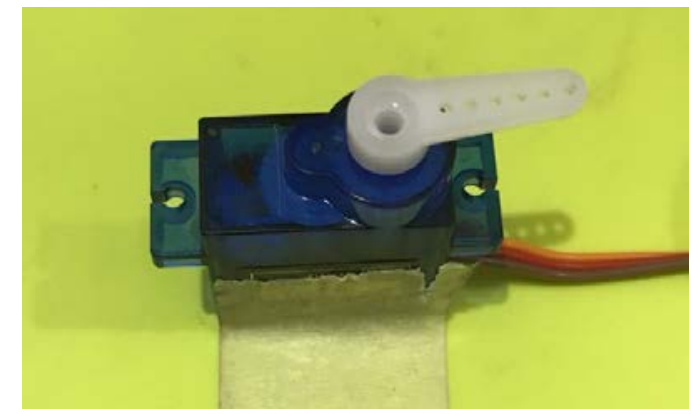


Gambar 10. Posisi servo dalam keadaan terkunci

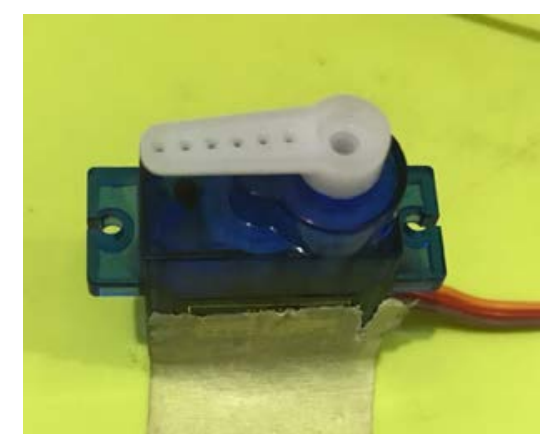

Gambar 11. Posisi servo dalam keadaan terbuka

Berdasarkan proses pengujian yang dilakukan pada motor servo, diperlihatkan pada Tabel 1 perbandingan pulse yang diberikan untuk menentukan posisi servo.

Tabel 2. Data Penentuan Posisi Servo

\begin{tabular}{|c|c|c|l|}
\hline No. & PWM & Sudut & O/C \\
\hline 1 & $1 \mathrm{~ms}$ & $0^{\circ}$ & Close \\
\hline 2 & $1.5 \mathrm{~ms}$ & $90^{\circ}$ & Close \\
\hline 3 & $2 \mathrm{~ms}$ & $180^{\circ}$ & Open \\
\hline
\end{tabular}

\subsection{Pengujian dan pembahasan rangkaian Bluetooth}

Pada pengujian bluetooth, user menghubungkan bluetooth pada android dengan Bluetooth mikrokontroller untuk melakukan pairing. Log in dengan memasukkan password yang diinginkan dan menekan tombol " $E$ ", kemudian masuk ke tampilan "controller $B$ " untuk memberikan perintah pada alat. Tampilan controller B pada bluetooth android dapat dilihat pada Gambar 12.

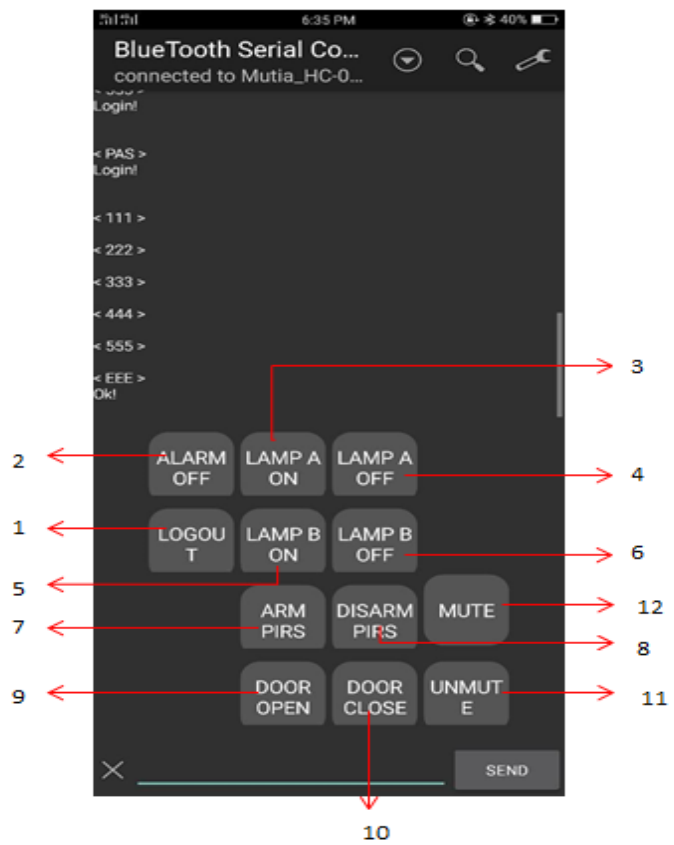

Gambar 12. Tampilan controller B pada Bluetooth android

\subsection{Pengujian dan pembahasan Sensor PIR}

Pengujian rangkaian sensor PIR untuk mengetahui sensor dapat bekerja dengan baik saat mendeteksi adanya gerakan objek, menghasilkan lampu menyala secara otomatis sesuai perencanaan dengan jarak maksimal 5 $\mathrm{m}$ yang telah terhubung dengan mikrokontroller. Pengujian sensor PIR dapat dilihat pada Gambar 13.

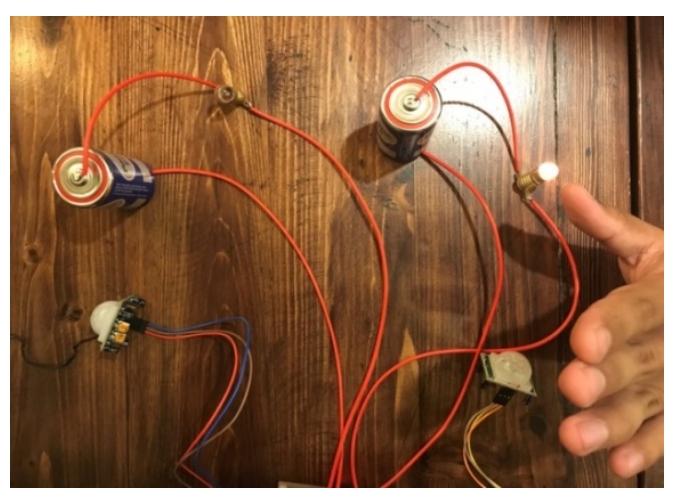

Gambar 13. Pengujian Sensor PIR 1

4.6. Cara mengoperasikan prototype secara keseluruhan 
1. Input password yang sudah dikehendaki . Jika password yang dimasukkan benar, maka kunci akan terbuka selama 5 detik dan kemudian terkunci kembali. Jika password yang dimasukkan salah sebanyak 3 kali, otomatis buzzer akan berbunyi.

2. Pada perangkat prototype terdapat dua buah sensor PIR yang mendeteksi pergerakan. Sensor ini memberikan pulsa kepada mikrokontroller yang diteruskan menjadi sebuah perintah ke lampu berupa 1 (ON) dan 0 (OFF), sehingga menghasilkan lampu menyala secara otomatis apabila terdeteksi gerakan.

\section{KESIMPULAN}

1. Prototype pengaman rumah dari bahaya pencurian berbasis mikrokontroller melalui komunikasi bluetooth telah berhasil direalisasikan.

2. Motor servo sudah dapat membuka dan mengunci dengan memasukkan password yang benar. Pengaturan ON/OFF lampu penerangan, tampilan informasi pada LCD, serta ON/OFF sensor PIR dari handphone android melalui komunikasi Bluetooth telah sesuai dengan perencanaan.

\section{DAFTAR PUSTAKA}

[1] Saftari, Firmansyah. Proyek Robotik Keren dengan Arduino. Jakarta: PT. Elex Media Komputindo. 2015.

[2] Arduino. Arduino UNO. 2019. Available at : https://www.arduino.cc/ diakses tanggal 26 Februari 2019.

[3] Itead Studio. Bluetooth To Serial Port Module. 2010. Available at : https://iteadstudio.com/ diakses tanggal 4 november 2018.
[4] Munandar, A. Liquid Crystal Display (LCD) 16x2. 2012. http://www.leselektronika.com/2012 /06/liguid-crystal-display-Icd-16x2.html Diakses tanggal 5 Oktober 2018.

[5] Kesuma IBD, Sudarma M., Swamardika IBA., Rancang Bangun Sistem Pengaman Berbasis Arduino Uno, E-Journal SPEKTRUM Vol. 3, No. 2. (2016)

[6] Adafruit Industries. PIR Motion Sensor. 2018. Available at : https://www.adafruit.com/ Diakses tanggal 27 Desember 2018.

[7] Andani, Christoforous Y, dkk. Sistem Kendali Servo Posisi dan Kecepatan Motor dengan Programmable Logic Control (PLC). Jurnal Ilmiah Foristek Vol.11.No.2. (2011) 